Clark University

Clark Digital Commons

Some Variables Affecting the Behaviour of Irus Macaques in

Dyadic Encounters

Nicholas S. Thompson 


\title{
SOME VARIABLES AFFECTING THE BEHAVIOUR OF IRUS MACAQUES IN DYADIC ENCOUNTERS*
}

\author{
BY NICHOLAS S. THOMPSON \\ Department of Psychology, University of California, Berkeley $\dagger$
}

The communication systems of baboons and macaques have been the subject of numerous recent investigations conducted in the field (Altmann, 1962; Kummer \& Kurt, 1963; Hall \& DeVore, 1965; and works cited therein) and in zoos (Kummer, 1957; Goustard, 1961, 1963). To observe and analyse in the laboratory the operation of one of these communication systems was the goal of the present experiment. The basic plan was to expose monkeys to a standardized social situation and to note changes in their communicative behaviour as aspects of this situation were varied. The standardized social situation chosen for this experiment was dyadic encounters between individuals which were strangers at the beginning of the experiment.

Dyadic encounters were chosen with two distinct purposes in mind. First, dyads of strangers, confronted in the laboratory are not affected by two influences thought to be extremely important in determining behaviour in the wild. Their behaviour is influenced neither by an extended history of previous interactions with one another nor by the ongoing behaviour of a surrounding group of animals. Insofar as their behaviour retains its wild form in laboratory encounters, it can be shown to be independent of these possible influences. Thus one major purpose of this study was simply to describe the behaviour of dyads in their first few meetings.

Secondly, dyadic encounters provide an opportunity to demonstrate experimentally the operation of the communication system. In group encounters heretofore described in the literature (e.g. Kawai, 1960; Bernstein \& Mason, 1963; Bernstein, 1964) and in dyadic encounters previously observed in my own laboratory, the amount of aggression and gesturing was initially high, then decreased. This decrease presumably resulted from tactile, visual, olfactory, and

*Supported by Public Health Service fellowship No. 4-F1-MH-17, 109 from the National Institute of Mental Health.

$†$ Present address: Department of Psychology, Swarthmore College, Swarthmore, Pennsylvania. auditory interaction between the animals during the early stages of their acquaintance. Experimental interference with one or more of the channels of social interaction during early acquaintance should therefore modify the extent and nature of interaction seen subsequently. Thus the second major purpose of the study was formally to demonstrate an effect of communication and to identify, if possible, the effective channel.

\begin{abstract}
Method
Subjects

Subjects were twelve Macaca irus. They were six males and six females ranging from young juveniles to young adults in both sexes. All were wild born, but had been maintained for over a year in the laboratory prior to the beginning of the experiment. They were always housed in pairs, with barriers arranged to preclude the exchange of visual signals between animals not actually housed together. Each subject was thoroughly adapted to the apparatus and to the testing routines.

The procedures of this experiment were carried out on the 66 possible dyads of these 12 animals excluding five which were cagemate pairs. The 61 pairs were assigned to three experimental groups equalized approximately for total number of pairings, for sex, and for age.
\end{abstract}

\section{Apparatus}

The observation cage was a plastic and wood structure approximately $6 \mathrm{ft}$ long by $2 \frac{1}{2} \mathrm{ft}$ high by $4 \mathrm{ft}$ deep with guillotine doors at either end. The floor was marked into eight equal-sized rectangles to aid recording of location. The cage was constructed in two units, each of the same height and depth as the whole cage and half as long. It could be rapidly partitioned into two adjacent compartments by sliding a barrier between the two units. Two sheets of plastic, one opaque and one clear, were available for this purpose.

Behaviour in the observation cage was photographed automatically by a $16 \mathrm{~mm}$ motion 
picture camera with a time-lapse mechanism which made exposures of $\frac{1}{30} \mathrm{sec}$ every second.

\section{Procedure}

Each of the 61 pairs was placed in the observation cage for two 10 -min observation periods spaced approximately 2 months apart. During these periods, no barrier separated the members of each pair. In the interim between the two observation periods, each pair was placed in the observation cage for four additional 10-min periods. These were conducted under one of three acquaintance conditions. The pairings of the Opaque barrier group were 'acquainted' on opposite sides of an opaque barrier, a condition which probably amounted to no acquaintance at all. The pairings of the Clear barrier group were acquainted on opposite sides of a transparent wall; they could see but could not touch one another. The pairings of the No barrier group were acquainted without any barrier. Thus the Clear barrier group had a total of 40 extra min to engage in visual contact and the No barrier group, a total of 40 extra min to engage in physical and visual contact.

\section{Dependent Variables}

Behaviour during the two observation periods was filmed at a rate of one frame every sec. Seven behaviour categories were described from the film record and are listed in Table I. They were mutually exclusive in the sense that only one category could be scored for an animal at a time. To be scored, a given behavioural act had to be identified in a minimum of two consecutive frames. Behaviours continuing beyond the 2-sec minimum were scored once for each 5 -sec period in which they occurred. Thus the maximum number of behaviours scoreable for any 10 -min observation period was 120 .

A measure was also taken of the average separation maintained between the two members of a pair. This measure was called the distance score. Every $5 \mathrm{sec}$ each animal's location was noted in terms of the eight rectangles on the floor. From the locations, the distance between the animals was scored on an arbitrary scale which ranged from 0 (touching) to 4.5 (in opposite corners of the apparatus).

\section{Results}

The results are presented in two parts, corresponding to the two major purposes of the investigation. The first part presents data describing the behaviour of dyads. These data were calculated by adding the behaviour frequencies of the first and second observation periods to make a total frequency of each category for each of the 61 pairs. The second part presents data describing the effects of the three acquaintance conditions. These data were obtained by subtracting each pair's first period frequencies from its second period frequencies, obtaining thus the change that each pair showed from first to second observation period.

Table I. The Social Behaviour Categories and Their Definitions

\begin{tabular}{|c|c|}
\hline Category & Definition \\
\hline Fight & $\begin{array}{l}\text { Biting or rough handling of one animal by another. Rough handling defined as any manipulation of } \\
\text { such force as to cause the filmed image of the manipulated animal's head and/or body to be blurred }\end{array}$ \\
\hline Chase & On three successive frames, one animal is moving towards the other while the latter is moving away \\
\hline Mount & $\begin{array}{l}\text { The 'normal' dorsoventral sexual mount (Altman, 1962, p. 416). Mounter places hands on the other's } \\
\text { haunches and grasps the other's ankles with his hind feet }\end{array}$ \\
\hline Atypical mount & $\begin{array}{l}\text { One animal brings his genitals into contact with the body of another in a manner other than typical } \\
\text { Mount. The mount may be atypical in that the mounter approaches an inappropriate region of the } \\
\text { body (head, back etc.) or approaches the appropriate region in an inappropriate fashion (pulling } \\
\text { the other animal down on top of him etc.) }\end{array}$ \\
\hline $\begin{array}{l}\text { Anogenital } \\
\text { inspection }\end{array}$ & $\begin{array}{l}\text { Bringing the nose close to or manipulating with hand or mouth the genital region of another. Be- } \\
\text { haviours scored in this category ranged (with all intergradations) from grooming of the anogenital } \\
\text { region to picking at it with the index finger of one hand to mouthing or smelling it }\end{array}$ \\
\hline Present & $\begin{array}{l}\text { Standing still on four feet for two successive frames with tail raised or averted from the genital region } \\
\text { and with hind quarters oriented toward the other animal }\end{array}$ \\
\hline Groom & Manipulating with two hands the fur of another \\
\hline
\end{tabular}


Table II. The Effect of Sex of Pair Members upon Behaviour Frequencies and Interindividual Distance in the Pair

\begin{tabular}{|c|c|c|c|c|c|}
\hline \multirow[b]{2}{*}{ Fight } & \multicolumn{3}{|c|}{$\begin{array}{l}\text { Sex subgroup of pairs } \\
\delta \delta^{\lambda}\end{array}$} & $\begin{array}{c}\text { All } \\
\text { pairs }\end{array}$ & $\boldsymbol{P}<$ \\
\hline & $24 \cdot 60$ & 1.55 & 0.46 & 6.95 & 0.001 \\
\hline Chase & $2 \cdot 47$ & $2 \cdot 61$ & 0.33 & 2.00 & 0.02 \\
\hline Mount & $4 \cdot 80$ & 23.03 & 0.00 & $12 \cdot 89$ & 0.001 \\
\hline Atypical mount & $4 \cdot 13$ & $5 \cdot 29$ & 0.13 & $3 \cdot 74$ & 0.05 \\
\hline Anogenital inspection & 1.53 & $14 \cdot 19$ & $6 \cdot 40$ & $9 \cdot 16$ & 0.001 \\
\hline Present & 0.93 & $2 \cdot 55$ & $3 \cdot 40$ & $2 \cdot 36$ & 0.05 \\
\hline Groom & 3.93 & $14 \cdot 29$ & $24 \cdot 47$ & 14.98 & 0.02 \\
\hline Total behaviour & $42 \cdot 40$ & $63 \cdot 48$ & $38 \cdot 20$ & $52 \cdot 08$ & 0.02 \\
\hline Distance & $2 \cdot 45$ & 1.97 & $2 \cdot 37$ & $2 \cdot 19$ & $0 \cdot 10$ \\
\hline
\end{tabular}

Significance levels are the outcome of an extended median test of the three sex subgroups.

\section{General Observations}

The average time spent doing any of the activities listed in Table I was quite little-of the order of $4 \mathrm{~min}$ in each pair's $20 \mathrm{~min}$ of observation-and highly variable from pair to pair (Table II). Grooming, mounting, and anogenital inspection were the most common activities. Male-male pairings devoted their time principally to fighting, female-female pairings to grooming and inspecting, and male-female pairs to mounting, grooming and inspecting. Average distance between members of a pair was high in homosexual pairings, low in heterosexual pairings.

In the 31 male-female pairings, the males performed most of the scoreable behaviour (Table III). The behaviours fighting, chasing, mounting, atypical mounting, and anogenital inspection were performed almost exclusively by males. Only presenting and grooming were performed frequently by females.

\section{The Effects of Acquaintance}

Table IV shows the change in frequency or score that occurred in each acquaintance group for each of the categories. A plus sign designates an increase from the first to the second observation period, a minus sign a decrease. Changes in frequency significant at the $0 \cdot 10$ level or better are starred; significance data on a KruskalWallis test comparing changes in the three groups are given in the final column, The additional
Table III. The Percentage of Each Behaviour Performed by the Male Members of Male-Female Pairs

\begin{tabular}{l|cc}
\hline & $\begin{array}{c}\text { Total } \\
\text { scorings }\end{array}$ & $\begin{array}{c}\text { Per cent } \\
\text { by male }\end{array}$ \\
\hline Fight & 48 & $100 \%$ \\
Chase & 80 & $100 \%$ \\
Mount & 714 & $100 \%$ \\
Atypical mount & 164 & $100 \%$ \\
Anogenital inspection & 440 & $84 \%$ \\
Present & 79 & $11 \%$ \\
Groom & 407 & $47 \%$ \\
\hline Total behaviour & 1932 & $82 \%$ \\
\hline
\end{tabular}

opportunity for touch had three effects on the pairings of the No barrier group. These pairings decreased the frequency of their grooming, decreased the total frequency of social behaviours, and increased their average distance, particularly in the latter half of the observation period.

The additional visual experience of the Clear Barrier group on the other hand, had no apparent effect on their behaviour. In all three cases in which the No barrier group differed markedly from the Opaque group, the Clear group's value was close to the Opaque group's value. These results suggest that the pairs of the Clear 
Table IV. The Effect of the Three Acquaintance Conditions upon Mean Behaviour Frequencies and Distance

\begin{tabular}{l|ccc|c}
\hline & \multicolumn{3}{|c|}{ Experimental group } & $\begin{array}{c}\text { Significance } \\
\text { of differences } \\
\text { between groups }\end{array}$ \\
\cline { 2 - 5 } Fight & Opaque & Clear & No barrier & ns \\
\cline { 2 - 4 } Chase & +0.85 & +1.71 & $-2.75^{*}$ & $n$ \\
Mount & $-1.70^{* *}$ & -0.57 & -0.30 & $\mathrm{~ns}$ \\
Atyp. Mnt & +2.00 & +1.19 & +1.55 & $\mathrm{~ns}$ \\
Anogen. Insp. & $-1.85^{* *}$ & -1.86 & $-3.40^{* * *}$ & $\mathrm{~ns}$ \\
Present & -1.90 & -0.43 & -1.30 & $\mathrm{~ns}$ \\
Groom & +0.45 & +0.19 & -0.65 & $\mathrm{~ns}$ \\
\hline Total behaviour & +4.75 & +3.62 & $-5.25^{* * *}$ & 0.01 \\
Distance & +2.60 & +3.86 & $-12.10^{* * *}$ & 0.05 \\
\hline
\end{tabular}

Asterisks indicate that the change is significant (i.e. not 0 ) at the $0.10\left({ }^{*}\right), 0.05\left(^{* *}\right)$, or $0.02(* * *)$ level of significance.

Changes in the three groups are compared by a Kruskal-Wallis analysis of variance (Siegel, 1956).

barrier group did not use the opportunity for visual communication accorded to them.

\section{Summary}

1. The behaviour of the 61 pairings fit the general outline of wild macaque behaviour established in many field studies over the last decade. Thus the relatively high frequencies of fighting among males, of grooming among females, of mounting, grooming and inspecting among heterosexual pairs, and the predominance of non-aggressive behaviours overall-these patterns are all familiar from field studies. Such similarities between the present data and field data on this and related species suggest that many of the factors which determine sex roles in the wild are also present in dyads of the species isolated from their normal social and ecological conditions.

2. Throughout the history of field and zoo studies of primate social behaviour, distance between animals has been recognized as an important variable (Chance, 1954). Even in the confined situation of the present experiment, distance between two animals proved to be highly reliable and sensitive to a variety of influences. Thus the tendency for macaques spatially to display their social relationships is a robust phenomenon extending even to close confinement.
3. Successive encounters between animals resulted in a decrease in their total social contact, in their grooming, and an increase in their average distance. This effect was apparently dependent upon physical contact between the animals. Irus macaques have a variety of visual signals which potentially could be employed across a transparent barrier. But this experiment produced no evidence of such independent operation of the macaque's visual communication system.

\section{Acknowledgment}

I am indebted to my sponsor, Dr Gilbert $\mathbf{M}$. French, for his assistance and counsel at every stage of this investigation.

\section{R E F E R E N C E S}

Altmann, S. A. (1962). A field study of the sociobiology of rhesus monkeys, Macaca mullatta. Ann. N.Y. Acad. Sci., 102, 338-435.

Bernstein, I. S. (1964). The integration of rhesus monkeys introduced to a group. Folia Primat., 2, 50-63.

Bernstein, I. S. \& Mason, W. A. (1963). Group formation by rhesus monkeys. Anim. Behav., 11, 28-31.

Chance, M. R. A. (1954). Social structure of a colony of Macaca mulatta. Brit. J. Anim. Behav., 4, 1-13.

Goustard, M. (1961). La structure sociale d'une colonie de Macaca irus. An. Sci. Nat. Zool., ser. 12, 3, 287-322. 
Goustard, M. (1963). Introduction a l'étude de la communication vocale chez Macaca irus. An. Sci. Nat. Zool., ser. 12, 5.

Hall, K. R. L. \& DeVore, I. (1965). Baboon social behavior. In Primate Behavior (Ed. by DeVore I.). New York: Holt, Rinehart \& Winston.

Kawai, M. (1960). A field experiment on a process of group formation the Japanese monkey (Macaca fuscata). Primates, 2, 181-253.
Kummer, H. (1957). Soziales Verhalten einer Mantelpavian-Gruppe. Schweiz. Z. Psychol., No. 33.

Kummer, H. \& Kurt, F. (1963). Social units of a freeliving population of Hamadryas Baboons. Folia Primat., 1, 4-19.

Siegel, S. (1956). Nonparametric Statistics for the Behavioral Sciences. New York: McGraw-Hill.

(Received 23 November 1965; revised 3 January 1967; Ms. number: A392) 